\title{
Expression of Thymidylate Synthase in Human Non-small Cell Lung Cancer
}

\author{
Yosuke Otake, ${ }^{1}$ Fumihiro Tanaka, ${ }^{1}$ Kazuhiro Yanagihara, ${ }^{1}$ Shigeki Hitomi, ${ }^{1}$ Hiroyuki Okabe, ${ }^{3}$ \\ Masakazu Fukushima ${ }^{3}$ and Hiromi $\mathrm{Wada}^{2,4}$ \\ ${ }^{1}$ Department of Thoracic Surgery, Kyoto University Hospital, ${ }^{2}$ Department of Medical Systems Control, \\ Institute for Frontier Medical Sciences, Kyoto University, 53 Shogoin, Kawahara-cho, Sakyo-ku, Kyoto \\ 606-8397 and ${ }^{3}$ Cancer Research Laboratory, Hanno Research Center, Taiho Pharmaceutical Co., Ltd., 1 - \\ 27 Misugidai, Hanno, Saitama 357-0041
}

\begin{abstract}
5-Fluorouracil (5-FU) has been used worldwide, and the correlation between its effects and thymidylate synthase (TS) expression has been reported in gastrointestinal malignancy. But the significance of TS expression for 5-FU-based chemotherapy has rarely been reported in non-small cell lung cancer (NSCLC). We investigated surgically resected specimens of 23 consecutive patients with previously untreated NSCLC. We used immunohistochemistry and western blot analysis with anti-TS polyclonal antibody to evaluate the existence of TS, and fluorodeoxyuridine-5'-monophosphate (FdUMP) binding assay to evaluate the enzymic activity of TS. We found that 14 samples $\mathbf{6 0 . 9 \% )}$ were positive immunohistochemically, and that the results of immunohistochemistry closely reflected the enzymic activity measured by FdUMP binding assay (ranging from 1.8 to 56.9 $\mathrm{pmol} / \mathrm{g}$ protein). These results seem to support our experience that 5-FU and its derivatives are clinically significantly effective as a postoperative adjuvant chemotherapy against NSCLC.
\end{abstract}

Key words: Thymidylate synthase - Non-small cell lung cancer — Protein expression — Enzymic activity — Chemotherapy

Thymidylate synthase (TS) is an important target enzyme for 5-fluorouracil (5-FU), because it catalyzes an essential step in DNA synthesis: methylation of deoxyuridine-5'-monophosphate (dUMP) to deoxythymidine-5' monophosphate (dTMP), which is an important substrate for DNA synthesis (Fig. 1). When 5-FU is administered, it is converted to fluorodeoxyuridine- $5^{\prime}$-monophosphate (FdUMP), which forms a ternary complex with TS and 5,10-methylene-tetrahydrofolate (m-THF). The ternary complex is an extremely stable, tight-binding covalent complex, and consequently FdUMP prevents methylation of dUMP by TS and inhibits DNA synthesis. ${ }^{1)}$ 5-FU and its derivatives have been used worldwide. The effectiveness of these drugs is well proven, and has been reported to correlate with the expression of TS in gastrointestinal malignancy. ${ }^{2-5)}$ On the other hand, the significance of TS expression for 5-FU based chemotherapy has not been well investigated in non-small cell lung cancer (NSCLC), because 5-FU and its derivatives have not been thought to be effective against NSCLC in general. However, their administration as postoperative adjuvant chemotherapy for NSCLC can be effective. ${ }^{6-8)}$ We also previously reported that postoperative biochemical modulation (BCM) therapy using 5-FU and UFT (a combination drug of tegafur and

This work was presented in part at 8th World Conference on Lung Cancer, Dublin, Ireland, August, 1997.

${ }^{4}$ To whom all correspondence should be addressed.

E-mail:wada@frontier.kyoto-u.ac.jp uracil in a molar ratio of 1:4) combined with cisplatin (CDDP) is effective in advanced NSCLC. ${ }^{9)}$ These reports suggest that TS controls DNA synthesis in NSCLC cells as well, and that TS can be an important target enzyme for 5-FU in NSCLC. There is no report on the enzymic activity of TS in NSCLC tissue. This prompted us to investigate the expression of TS by immunohistochemistry and western blot analysis, as well as its enzymic activity by FdUMP binding assay in NSCLC tissue.

\section{MATERIALS AND METHODS}

Patients (Table I) A total of 23 consecutive patients with previously untreated NSCLC were analyzed. They were treated surgically in Kyoto University Hospital from September 1995 to March 1996, and were diagnosed pathologically as NSCLC. There were 15 men and 8 women who ranged in age from 45 to 80 years (average 63.5). Informed consent was obtained from all the patients. Pathological tumor types were 17 adenocarcinomas, 3 squamous cell carcinomas, 1 large cell carcinoma, 1 adenosquamous cell carcinoma, and 1 atypical carcinoid. Fifteen of the 23 patients were diagnosed as having pathological stage I, 1 as stage II, 6 as stage IIIA, and 1 as stage IIIB. The pathological diagnosis was based on the WHO classification, ${ }^{10)}$ and the staging of all patients was made according to the International Staging System for Lung Cancer. ${ }^{11)}$ Tissue samples Tumor parts of the surgical specimen were immediately fixed in $10 \%$ formalin and stored at 

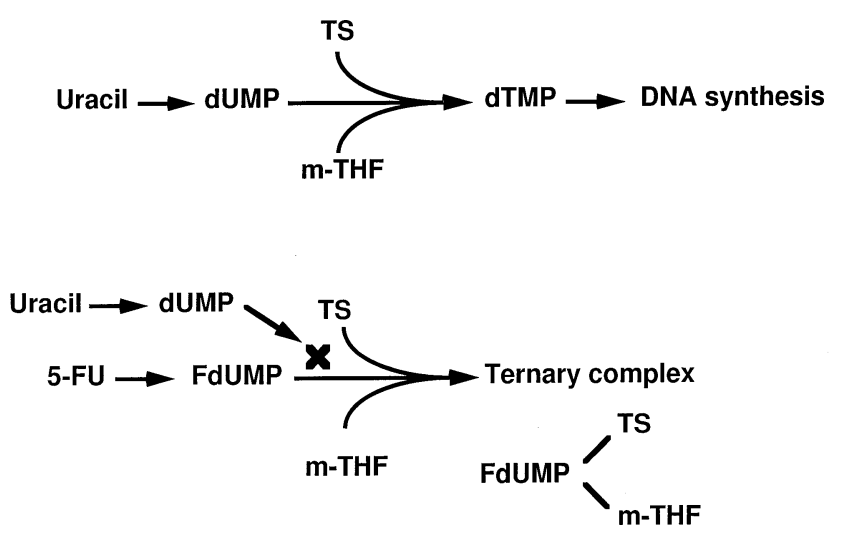

Fig. 1. Mechanism of DNA synthesis inhibition by 5-fluorouracil (5-FU). Thymidylate synthase (TS) catalyzes an essential step in DNA synthesis: methylation of deoxyuridine- $5^{\prime}$-monophosphate (dUMP) to deoxythymidine-5'-monophosphate (dTMP). 5-Fluorouracil (5-FU) inhibits DNA synthesis by forming a stable covalent ternary complex consisting of fluorodeoxyuridine-5'-monophosphate (FdUMP), 5,10-methylenetetrahydrofolate (m-THF) and thymidylate synthase (TS).

room temperature (RT) for immunohistochemical staining, or freshly frozen with liquid nitrogen and stored at $-70^{\circ} \mathrm{C}$ for western blot analysis and FdUMP binding assay.

Preparation of anti-TS polyclonal antibody The antiTS polyclonal antibody used for immunohistochemical staining and western blot analysis was produced by one of us (M.F.). The antibody was prepared by immunizing male New Zealand White rabbits with recombinant TS protein, prepared in human placenta and human lung carcinoma cell line (Lu-99) by using standard molecular biological techniques. ${ }^{12)}$

Reagents Peroxidase Blocking Reagent was purchased from DAKO Co., Ltd. (Santa Barbara, CA), and diaminobenzidine tetrahydrochloride (DAB) was purchased from Wako Co., Ltd. (Osaka). Non-immunized normal goat serum, biotinylated goat anti-rabbit IgG and streptavidinbiotinylated peroxidase complex were obtained from a VECTASTAIN Elite ABC kit purchased from Vector Co., Ltd. (Burlingame, CA). All other chemicals were commercial products of analytical grade.

Immunohistochemical staining Formalin-fixed and paraffin-embedded $4 \mu \mathrm{m}$ thick tissue sections were studied by immunohistochemistry. After deparaffinization, the tissue sections were preincubated with Peroxidase Blocking Reagent and non-immunized normal goat serum, and incubated with anti-TS polyclonal antibody $(275 \mathrm{pg} / \mathrm{ml})$ as a primary antibody overnight at $4{ }^{\circ} \mathrm{C}$. Biotinylated goat antirabbit IgG was applied as a secondary antibody for $30 \mathrm{~min}$ at RT, followed by streptavidin-biotinylated peroxidase complex for $60 \mathrm{~min}$ at RT. Peroxidase activity was visual-
Table I. Characteristics of the Patients

\begin{tabular}{cc}
\hline \hline & $n^{\mathrm{a})}$ \\
\hline Gender & \\
Male & 15 \\
Female & 8 \\
Age & \\
40-49 & 1 \\
$50-59$ & 6 \\
$60-69$ & 11 \\
$70-79$ & 4 \\
$80-89$ & 1 \\
Pathological tumor type & \\
Adeno & 17 \\
Squamous cell & 3 \\
Large cell & 1 \\
Adenosquamous & 1 \\
Carcinoid & 1 \\
Differentiation ${ }^{\text {b) }}$ & \\
Well & 14 \\
Moderate & 5 \\
Poorly & 2 \\
Pathological stage & \\
I & 15 \\
II & 1 \\
IIIA & 6 \\
IIIB & 1 \\
\hline
\end{tabular}

a) Number of patients.

b) Large cell and carcinoid were not included.

ized with DAB solution $(1 \mathrm{mg} / \mathrm{ml} \mathrm{DAB}$ and $0.001 \%$ hydrogen peroxide in $0.1 \mathrm{M}$ Tris- $\mathrm{HCl} \mathrm{pH}$ 7.2) for $5 \mathrm{~min}$ at RT. Counter-staining was performed with hematoxylin for $1 \mathrm{~min}$. A negative control was performed without primary antibody for each section. Slide glasses were examined separately by two observers (Y.O. and F.T.), who did not know the clinical characteristics of the patients. One hundred tumor cells were counted in 5 random visual fields of each slide glass. The immunohistochemically positive rates were determined from a total of 500 tumor cells. Sections in which more than $10 \%$ of tumor cells were stained were judged to be TS-positive, and otherwise, TSnegative.

Western blot analysis Tissue samples stored at $-70^{\circ} \mathrm{C}$ were defrozen, homogenized with $200 \mathrm{~m} M$ Tris- $\mathrm{HCl}(\mathrm{pH}$ 7.4, containing $20 \mathrm{~m} M$ 2-mercaptoethanol, $15 \mathrm{~m} M$ cytidine-5'-monophosphate (5'-CMP) and $100 \mathrm{mM} \mathrm{NaF}$ ) and centrifuged at $105,000 \mathrm{~g}$ for $60 \mathrm{~min}$. The supernatant was loaded on $12.5 \%$ polyacrylamide gel (protein content was $25 \mu \mathrm{g} / \mathrm{lane}$ ), and the proteins were electrically blotted to poly(vinylidene difluoride) (PVDF) membrane overnight at $4^{\circ} \mathrm{C}$. TS expression was detected by applying anti-TS polyclonal antibody as a primary antibody $(1 \mu \mathrm{g} / \mathrm{ml})$ overnight at $4^{\circ} \mathrm{C}$, and biotinylated goat anti-rabbit $\operatorname{IgG}$ as a 
secondary antibody for $60 \mathrm{~min}$ at RT. Peroxidase activity was visualized with DAB solution $(1 \mathrm{mg} / \mathrm{ml} \mathrm{DAB}$ and $0.001 \%$ hydrogen peroxide in $0.1 M$ tris buffer solution $\mathrm{pH}$ 7.2) for $5 \mathrm{~min}$ at RT.

FdUMP binding assay Tissue samples stored at $-70^{\circ} \mathrm{C}$ were defrozen, homogenized with 3 volumes of $200 \mathrm{~m} M$ Tris- $\mathrm{HCl}(\mathrm{pH} 8.0$, containing $20 \mathrm{mM}$ 2-mercaptoethanol, $100 \mathrm{~m} M \mathrm{NaF}$ and $15 \mathrm{~m} M 5^{\prime}-\mathrm{CMP}$ ) and centrifuged at $105,000 \mathrm{~g}$ for $60 \mathrm{~min}$. According to the method of Spears et al. ${ }^{13)}$ the supernatant was used for the determination of TS activity by addition of an excess of $\left[6-{ }^{3} \mathrm{H}\right]$ FdUMP. Protein content was determined using the Bio-Rad protein assay kit (Veementaal, The Netherlands).

Statistical analysis Statistical analysis was performed with the 2-tailed unpaired $t$-test using the "SPSS for Windows" software system (SPSS, Chicago, IL).

\section{RESULTS}

Immunohistochemical staining Fourteen samples $(60.9 \%)$ out of the total of 23 were revealed to be TS-positive by immunohistochemistry. According to pathological types, $11(64.7 \%)$ of 17 adenocarcinomas and one of three squamous cell carcinomas were TS-positive. One large cell carcinoma was TS-positive, and the adenosquamous cell carcinoma and atypical carcinoid were TS-negative (Table II). Our antibody recognized not only malignant cells, but also endothelial cells, red blood cells and normal squamous cells. However, it was straightforward to judge the staining pattern of tumor cells by comparing the findings with those of HE staining (Fig. 2).

Western blot analysis TS protein was detected as a band of $37 \mathrm{kDa}$ (Fig. 3). The density of the band corresponded to the TS enzymic activity in FdUMP binding assay as mentioned below.

FdUMP binding assay (Table III) TS enzymic activity evaluated by FdUMP binding assay ranged from 1.8 to $56.9 \mathrm{pmol} / \mathrm{g}$ protein (average 18.5, median 13.0). According to pathological type, it ranged from 3.8 to $37.8 \mathrm{pmol} / \mathrm{g}$ protein (average 13.4, median 10.0) in the 17 adenocarcinomas and from 1.8 to 54.9 (average 24.7, median 17.4) in

Table II. Immunohistochemical Staining with Anti-TS Polyclonal Antibody in Human Non-small Cell Lung Cancer Tissue

\begin{tabular}{lrcccc}
\hline \hline & $n^{\text {a) }}$ & Positive & $\%$ & Negative & $\%$ \\
\hline Total & 23 & 14 & 60.9 & 9 & 39.1 \\
Adeno & 17 & 11 & 64.7 & 6 & 35.3 \\
Squamous cell & 3 & 1 & 33.3 & 2 & 66.7 \\
Large cell & 1 & 1 & 100 & 0 & 0 \\
Adenosquamous & 1 & 0 & 0 & 1 & 100 \\
Carcinoid & 1 & 0 & 0 & 1 & 100 \\
\hline
\end{tabular}

a) Number of patients. the three squamous cell carcinomas. There was no significant difference in TS enzymic activity in tumor tissue between adenocarcinoma and squamous cell carcinoma $(P=0.169)$. Comparing the result with that of TS immunohistochemistry, TS activity by FdUMP binding assay ranged from 1.8 to $37.8 \mathrm{pmol} / \mathrm{g}$ protein (average 17.4, median 16.8) in 14 samples of the TS-positive group, and

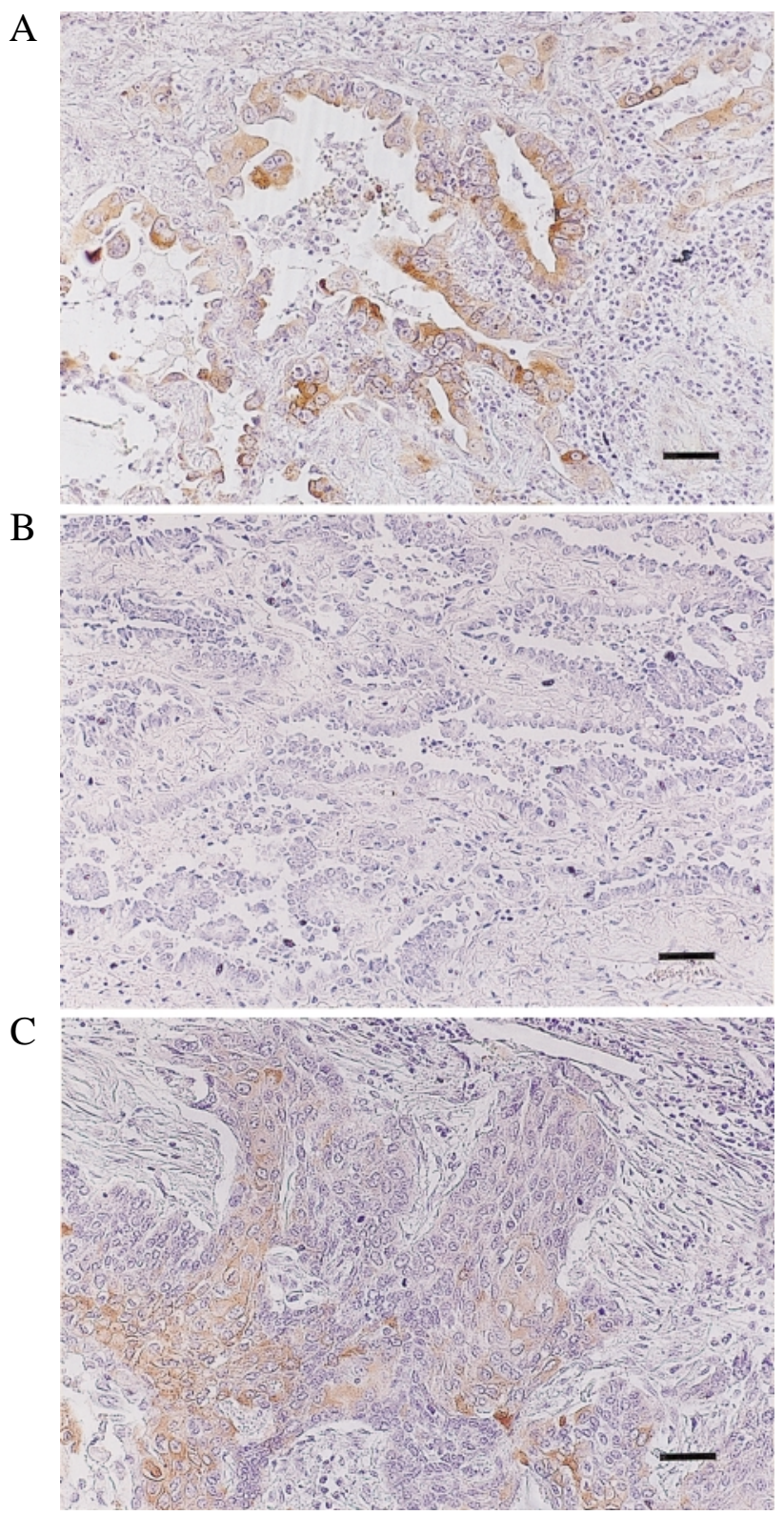

Fig. 2. Immunohistochemical detection of thymidylate synthase (TS) in non-small cell lung cancer tissue. A, adenocarcinoma revealed to be TS-positive; $\mathrm{B}$, TS-negative adenocarcinoma; $\mathrm{C}$, TS-positive squamous cell carcinoma. Magnification is 1:200. Scale bar is $100 \mu \mathrm{m}$. 
from 3.8 to $56.9 \mathrm{pmol} / \mathrm{g}$ protein (average 20.3, median 7.1) in 9 samples of the TS-negative group. But there was no significant difference in TS enzymic activity in tumor

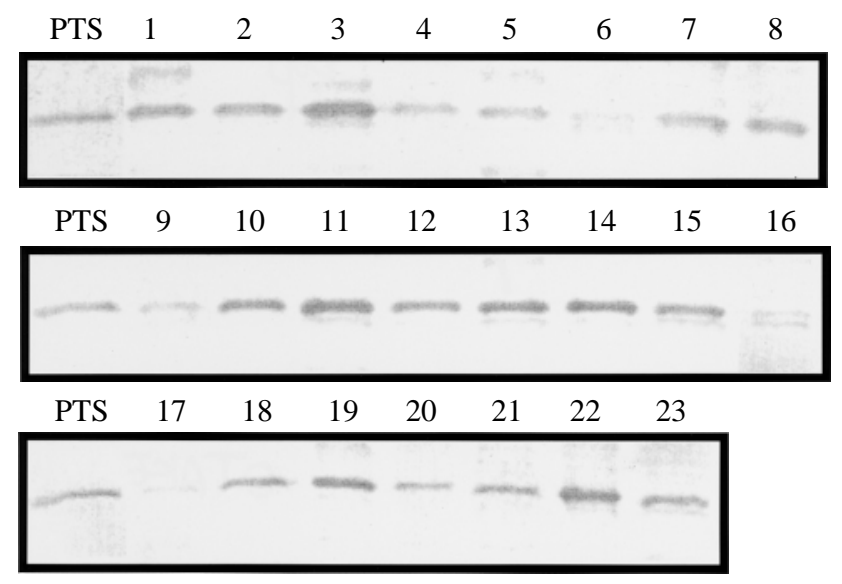

Fig. 3. Western blot analysis of thymidylate synthase (TS) in non-small cell lung cancer tissue with anti-TS polyclonal antibody. Purified recombinant TS was applied to PTS lanes $(0.23$ $\mu \mathrm{g} /$ lane). tissue between the TS-positive and TS-negative groups $(P=0.671)$. The results of TS immunohistochemistry, those of FdUMP binding assay and other information on the patients are listed in Table IV.

\section{DISCUSSION}

TS is a key enzyme that catalyzes an important step in DNA synthesis and is the main target of 5-FU based chemotherapy. 5-FU and its derivatives are widely used to

Table III. TS Enzymic Activity by FdUMP Binding Assay

\begin{tabular}{lrccc}
\hline \hline & $n^{\text {a) }}$ & Range $^{\text {b) }}$ & Average $^{\text {b) }}$ & Median $^{\text {b) }}$ \\
\hline Total & 23 & $1.8-56.9$ & 18.5 & 13.0 \\
Pathological types & & & & \\
$\quad$ Adeno & 17 & $3.8-37.8$ & 13.4 & 10.0 \\
$\quad$ Squamous cell & 3 & $1.8-54.9$ & 24.7 & 17.4 \\
TS immunohistochemistry & & & & \\
$\quad$ TS positive & 14 & $1.8-37.8$ & 17.4 & 16.8 \\
$\quad$ TS negative & 9 & $3.8-56.9$ & 20.3 & 7.1 \\
\hline
\end{tabular}

a) Number of patients.

b) $\mathrm{pmol} / \mathrm{g}$ protein.

Table IV. Relationship between Immunohistochemical Detection of TS-protein and TS Enzymic Activity Evaluated by FdUMP Binding Assay

\begin{tabular}{|c|c|c|c|c|c|c|}
\hline $\begin{array}{l}\text { Patient } \\
\text { No. }\end{array}$ & Age/gender & Pathology $y^{\text {a) }}$ & P-stage & Positive rate $(\%)$ & $\begin{array}{c}\text { Judgement } \\
\mathrm{P} \text { or } \mathrm{N}^{\mathrm{b})}\end{array}$ & TS-activity $^{\mathrm{c}}$ \\
\hline 1 & $80 / \mathrm{F}$ & Ad & I & 55.2 & $\mathrm{P}$ & 17.1 \\
\hline 2 & 73/M & $\mathrm{Sq}$ & IIIA & 66.6 & $\mathrm{P}$ & 17.4 \\
\hline 3 & $52 / \mathrm{M}$ & Ad & I & 72.8 & $\mathrm{P}$ & 37.8 \\
\hline 4 & $69 / \mathrm{M}$ & Ad & I & 78.8 & $\mathrm{P}$ & 6.4 \\
\hline 5 & $64 / F$ & Ad & I & 0.0 & $\mathrm{~N}$ & 7.1 \\
\hline 6 & 53/M & Ad & I & 1.2 & $\mathrm{~N}$ & 4.0 \\
\hline 7 & $76 / F$ & Ad & IIIA & 52.4 & $\mathrm{P}$ & 13.0 \\
\hline 8 & $57 / F$ & Ad & I & 98.2 & $\mathrm{P}$ & 11.4 \\
\hline 9 & $61 / \mathrm{M}$ & Ad & I & 4.4 & $\mathrm{~N}$ & 3.8 \\
\hline 10 & $62 / \mathrm{M}$ & Car & IIIA & 8.4 & $\mathrm{~N}$ & 36.2 \\
\hline 11 & 69/M & $\mathrm{AdSq}$ & I & 0.8 & $\mathrm{~N}$ & 56.9 \\
\hline 12 & $69 / \mathrm{M}$ & Ad & II & 75.2 & $\mathrm{P}$ & 23.9 \\
\hline 13 & $71 / \mathrm{M}$ & Ad & IIIA & 36.6 & $\mathrm{P}$ & 16.5 \\
\hline 14 & $73 / \mathrm{M}$ & $\mathrm{La}$ & I & 18.4 & $\mathrm{P}$ & 31.7 \\
\hline 15 & $65 / \mathrm{M}$ & Ad & IIIB & 32.2 & $\mathrm{P}$ & 10.0 \\
\hline 16 & $65 / \mathrm{M}$ & $\mathrm{Sq}$ & I & 65.4 & $\mathrm{P}$ & 1.8 \\
\hline 17 & $69 / \mathrm{F}$ & Ad & I & 6.8 & $\mathrm{~N}$ & 4.5 \\
\hline 18 & $52 / \mathrm{F}$ & Ad & IIIA & 50.0 & $\mathrm{P}$ & 19.9 \\
\hline 19 & $60 / \mathrm{F}$ & Ad & I & 78.6 & $\mathrm{P}$ & 26.5 \\
\hline 20 & $54 / \mathrm{F}$ & Ad & I & 3.6 & $\mathrm{~N}$ & 6.0 \\
\hline 21 & $54 / \mathrm{M}$ & Ad & I & 3.8 & $\mathrm{P}$ & 9.8 \\
\hline 22 & $67 / \mathrm{M}$ & $\mathrm{Sq}$ & I & 0.2 & $\mathrm{~N}$ & 54.9 \\
\hline 23 & $45 / \mathrm{M}$ & Ad & IIIA & 1.6 & $\mathrm{~N}$ & 9.4 \\
\hline
\end{tabular}

a) Ad, adenocarcinoma; Sq, squamous cell carcinoma; Car, atypical carcinoid; AdSq, adenosquamous cell carcinoma; La, large cell carcinoma.

b) $\mathrm{P}$, positive; $\mathrm{N}$, negative.

c) $\mathrm{pmol} / \mathrm{g}$ protein. 
treat gastrointestinal malignancy. TS expression in gastrointestinal malignancy has been extensively investigated, and it was reported that the presence and enzymic activity of TS were significantly correlated with sensitivity to 5FU, post-chemotherapeutic clinical course and prognosis of the patients. ${ }^{2-5)}$ In contrast, little information is available about TS and the clinical effects of 5-FU and its derivatives on NSCLC, because it has been generally believed that $5-\mathrm{FU}$ and its derivatives are ineffective against NSCLC.

However, we reported in a prospective randomized study that postoperative oral administration of UFT (400 $\mathrm{mg} /$ body, for a year) for NSCLC had a significantly beneficial effect as compared with surgery alone. $\left.{ }^{6}\right)$ Another Japanese group similarly reported that postoperative chemotherapy using CDDP $\left(66 \mathrm{mg} / \mathrm{m}^{2}\right)$, adriamycin $(26 \mathrm{mg} /$ $\left.\mathrm{m}^{2}\right)$ and UFT ( $8 \mathrm{mg} / \mathrm{kg} / \mathrm{day}$, for 6 months) for NSCLC had a significantly beneficial effect. ${ }^{7)}$ We also reported that BCM therapy using 5-FU and UFT combined with CDDP was effective against advanced NSCLC. ${ }^{8)}$ Thus, we investigated TS expression and its enzymic activity in NSCLC tissue.

In this study, we demonstrated the presence of TS and its enzymic activity in NSCLC tissue by immunohistochemical staining, western blot analysis and FdUMP binding assay.

A problem in this study is that the results of immunohistochemistry were not significantly correlated with the results of FdUMP binding assay. There may be two reasons for this discrepancy. One possibility is problems with the immunohistochemical technique, that is to say, the formalin fixation and paraffin-embedding procedure may mask the antigenicity of TS. The other is the possibility of contamination with various amounts of normal tissue in the samples for FdUMP binding assay. TS expression was reported to exist in normal lung tissue and to be generally lower than in tumor tissue. ${ }^{14,15}$ We confirmed that some normal tissues were stained positively by our antibody. Considering that TS is abundant in normal cells with active DNA synthesis, it seems likely that contamination with normal tissue caused the discrepancy between immunohistochemistry and FdUMP binding assay. The problem might be resolved by evaluation of more samples, because rather few samples were investigated in this study. Moreover, normal tissue stained positively by immunohistochemistry was considered to reflect genuine TS protein in normal tissue except red blood cells, because TS protein was detected as a single band by western blotting in our study.

Thus, immunohistochemical evaluation of TS protein expression seems to be possible even in formalin-fixed tumor sections, reflecting the results of TS enzymic activity measurement by FdUMP binding assay, although some exceptions were found. Immunohistochemical staining of formalin-fixed tumor sections is very useful to investigate TS expression in numerous samples retrospectively.

TS expression at the RNA level in gastrointestinal malignancy has been studied using the reverse transcription-polymerase chain reaction., ${ }^{2,5}$ Those investigators reported that patients with high TS mRNA expression had a lower response to 5-FU and its derivatives and a poorer prognosis. It was also reported that immunohistochemical TS protein expression and mRNA expression were highly correlated.

We found only one article that reported immunohistochemical TS expression in NSCLC, ${ }^{16)}$ in which the correlation between TS existence and sensitivity to postoperative chemotherapy using 5-FU, doxorubicin, and CDDP was studied. The results revealed that TS-positive patients had a significantly poor response to postoperative chemotherapy and a poor prognosis, as in the case of gastrointestinal malignancy. But in their study, the enzymic activity of TS in NSCLC was not investigated, and ours is the first report to determine the enzymic activity of TS in NSCLC by FdUMP binding assay.

5-FU and its derivatives require TS for effectiveness. Thus, 5-FU and its derivatives have the potential to be effective against NSCLC. But the number of samples was too small for us to decide how TS expression is related to drug sensitivity to 5-FU and its derivatives in NSCLC and how it influences the postoperative survival rate and disease-free survival. We should clarify the correlation between TS expression and drug sensitivity, postoperative survival rate and disease-free survival by investigating more samples in the future. We have already reported that p53 status is useful for predicting the efficacy of postoperative administration of UFT in completely resected NSCLC. ${ }^{17)}$ It would be of benefit to patients with NSCLC if the 5-FU based chemotherapeutic effect for each patient could be predicted from the TS information of a biopsy specimen, in conjunction with the p53 status.

We have demonstrated TS protein expression and its enzymic activity in NSCLC by immunohistochemistry and western blot analysis using anti-TS polyclonal antibody and FdUMP binding assay. This supports the idea that 5FU and its derivatives may be clinically effective against NSCLC, for which these drugs had been thought to be of little value.

\section{ACKNOWLEDGMENTS}

This work was supported in part by the Japan Society for the Promotion of Science (RFTF 96100204).

(Received June 21, 1999/Revised August 11, 1999/Accepted August 17, 1999) 


\section{REFERENCES}

1) Peters, G. J., van der Wilt, C. L., van Triest, B., CodacciPisanelli, G., Johnston, P. G., van Groeningen, C. J. and Pinedo, H. M. Thymidylate synthase and drug resistance. Eur. J. Cancer, 31A, 1299-1305 (1995).

2) Johnston, P. G., Lenz, H. J., Leichman, C. G., Danenberg, K. D., Allegra, C. J., Danenberg, P. V. and Leichman, L. Thymidylate synthase gene and protein expression correlate and are associated with response to 5-fluorouracil in human colorectal and gastric tumor. Cancer Res., 55, 1407-1412 (1995).

3) Johnston, P. G., Fisher, E. R., Rockette, H. E., Fisher, B., Wolmark, N., Drake, J. C., Chabner, B. A. and Allegra, C. J. The role of thymidylate synthase expression in prognosis and outcome of adjuvant chemotherapy in patients with rectal cancer. J. Clin. Oncol., 12, 2640-2647 (1994).

4) Peters, G. J., van der Wilt, C. L., van Groeningen, C. J., Smid, K. and Pinedo, H. M. Thymidylate synthase inhibition after administration of fluorouracil with or without leucovorin in colon cancer patients: implications for treatment with fluorouracil. J. Clin. Oncol., 12, 2035-2042 (1994).

5) Lenz, H. J., Leichman, C. G., Danenberg, K. D., Danenberg, P. V., Groshen, S., Cohen, H., Laine, L., Silberman, H., Baranda, J., Garcia, Y., Li, J. and Leichman, L. Thymidylate synthase mRNA level in adenocarcinoma of the stomach: a predictor for primary tumor response and overall survival. J. Clin. Oncol., 14, 176-182 (1995).

6) Wada, H., Hitomi, S., Teramatsu, T. and West Japan Study Group for Lung Cancer Surgery. Adjuvant chemotherapy after complete resection in non-small-cell lung cancer. $J$. Clin. Oncol., 14, 1048-1054 (1996).

7) Tanaka, F., Miyahara, R., Otake, Y., Yanagihara, K., Fukuse, T., Hitomi, S. and Wada, H. Advantage of postoperative oral administration of UFT (Tegafur and Uracil) for completely resected p-stage I-IIIa non-small cell lung cancer (NSCLC). Eur. J. Cardiothorac. Surg., 14, 256-262 (1998).

8) The Study Group of Adjuvant Chemotherapy for Lung Can- cer (Chube, Japan). A randomized trial of postoperative adjuvant chemotherapy in non-small-cell lung cancer (the second cooperative study). Eur. J. Surg. Oncol., 21, 69-77 (1995).

9) Tanaka, F., Otake, Y., Yanagihara, K., Fukuse, T., Hitomi, S. and Wada, H. Early phase II study of biochemical modulation chemotherapy (BCM) using 5-fluorouracil (5-FU) and cisplatin (CDDP) for advanced non-small cell lung carcinoma (NSCLC). Lung Cancer, 18 (Suppl. 1), 33 (1997).

10) World Health Organization. Histological typing on lung tumors. Tumori, 6, 253-272 (1981).

11) Mountain, C. F. A new international staging system for lung cancer. Chest, 89 (Suppl.), 225S-233S (1986).

12) Okabe, H., Tsujimoto, H. and Fukushima, M. Preparation of the antibodies against recombinant human thymidylate synthase for the detection of its intratumoral level and the application to sensitivity-study of 5-fluorouracil. Oncol. Rep., 4, 685-690 (1997).

13) Spears, C. P., Shahinian, A. H. and Moran, R. G. In vivo kinetics of thymidylate synthase inhibition in 5-fluorouracilsensitive and -resistant murine colon adenocarcinomas. Cancer Res., 42, 450-456 (1982).

14) Herzfeld, A. and Raper, S. M. Relative activities of thymidylate synthase and thymidylate kinase in rat tissues. Cancer Res., 40, 744-750 (1980).

15) Hashimoto, Y., Shiotani, T., Eble, J. N., Glover, J. L. and Weber, G. Increased thymidylate synthase (EC 2.1.1.45) activity in normal and neoplastic proliferation. Cancer Biochem. Biophys., 10, 1-10 (1988).

16) Folm, M. and Mattern, J. Elevated expression of thymidylate synthase in doxorubicin resistant human non small cell lung carcinomas. Anticancer Res., 12, 2293-2296 (1992).

17) Tanaka, F., Miyahara, R., Otake, Y., Yanagihara, K., Fukuse, T., Hitomi, S. and Wada, H. P53 and BCL-2 expression and the efficacy of postoperative oral administration of UFT for P-stage I, NSCLC. Proc. of ASCO, 14, 550a (1998). 